\title{
AVALIAÇÃO DE DIFERENTES FONTES DE NITROGÊNIO NA CULTURA DO CAFÉ
}

\author{
EVALUATION OF DIFFERENT SOURCES OF NITROGEN IN COFFEE \\ CULTURE \&
}
EVALUACIÓN DE DIFERENTES FUENTES DE NITRÓGENO EN EL CULTIVO DEL CAFÉ \&

Recebido em: 16/11/2021 - Aprovado em: 09/12/2021 - Publicado em: 17/12/2021

http://dx.doi.org/10.18011/bioeng2021v15n4p617-631

Elber Augusto Caixeta ${ }^{1}$ (elbercaixeta@hotmail.com)

Kleso Silva Franco Junior ${ }^{1}$ (kleso.junior@yahoo.com.br)

Giselle Prado Brigante1 (giselle.brigante@gmail.com)

Marcio de Souza Dias² (marciodesouzadias2013@gmail.com)

Marco Antônio Pereira de Avila ${ }^{3}$ (agrointegratecnologias@gmail.com)

${ }^{1}$ CESEP- Centro Superior de Ensino e Pesquisa de Machado. Machado, MG, Brasil.

2 Secretaria de Estado de Educação de Minas Gerais/SEE-MG-Serrania, MG, Brasil.

${ }^{3}$ Agrointegra. Sorocaba, SP, Brasil.

RESUMO

O equilíbrio nutricional do cafeeiro é fundamental para objetivar altas produtividades. O Nitrogênio é o nutriente mais exigido pela cultura do café, sendo seu fornecimento mais utilizado a partir de fontes de ureia, a qual é sujeita a perdas por volatilização de amônia quando aplicada sem incorporação ou baixos níveis de umidade no solo. Diante disso, buscou-se avaliar os efeitos de diferentes fontes de nitrogênio com diferentes tecnologias, na adubação de cafeeiro arábica em produção. Para isso, foi utilizando a cultivar Catucai Amarelo 24/137, e com aplicação de cinco fontes de nitrogênio: ureia complexada, ureia convencional, ureia de liberação controla, blend de ureia de liberação controlada com ureia protegida e ureia protegida. Conclui se que a ureia complexada proporcionou o melhor rendimento de litros de café colhido para produzir uma saca beneficiada e a ureia convencional em acumulo de $\mathrm{N}$ foliar.

Palavras-chave: Amonificação. Amônia. Coffea arabica. Nutrição. Volatilização. 


\section{INTRODUÇÃO}

O café é uma cultura de grande importância para o Brasil, sendo que, o país é o maior produtor e exportador mundial deste grão (ABIC, 2021). Entretanto, sabe-se que a produtividade média no país ainda é baixa quando comparado com o potencial que pode ser alcançado (MIRANDA, 2019).

Vários fatores interferem no crescimento e produtividade do cafeeiro, dentre eles pode-se citar o fator nutricional, em que nutrientes essenciais quando não supridos adequadamente podem afetar os processos metabólicos das plantas, podendo resultar em atrasos no desenvolvimento da mesma. Nesse sentido o nitrogênio destaca-se como papel fundamental para as plantas (EMATER, 2016).

Devido a grande contribuição para o crescimento socioeconômico das culturas cafeeiras, é necessário amplo conhecimento sobre a espécie. Ante o exposto, estudos e pesquisas têm possibilitado ainda mais avanços na cafeicultura desde sua implantação até a comercialização, reduzindo os riscos inerentes à atividade, e aumentando a qualidade da bebida.

Diante disso é que dos vários estudos direcionados à cafeicultura, tem sido dado devida importância às metodologias de fertilização. Essas pesquisas têm como intuito auxiliar o produtor na tomada de decisão a qual e quanto de adubo é o adequado para alavancar à produtividade e ao beneficiamento do café (EMBRAPA, 2018).

A pesquisa objetivou em avaliar os efeitos do fornecimento de $\mathrm{N}$, com fontes mais utilizadas de ureia para o cafeeiro, em relação aos teores do nutriente na folha, enfolhamento e produção.

\section{MATERIAIS E MÉTODOS}

O experimento foi conduzido na Fazenda Santa Cruz, localizada no Município de

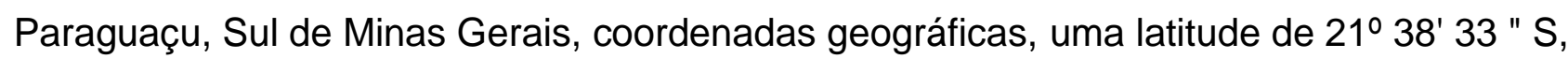
longitude de 45 48' 10" O, e altitude de $915 \mathrm{~m}$. O solo é caracterizado como Latossolo Vermelho distróficos de acordo com o Sistema Brasileiro de Classificação de Solos (SiBSC) Santos et al (2018). O clima é caracterizado Segundo Koppen, Cwa, quente e temperado, o inverno apresenta precipitação pluviométrica média de $169 \mathrm{~mm}$ e no verão em média de $1206 \mathrm{~mm}$. A temperatura média anual é de $20,6^{\circ} \mathrm{C}$ e índice pluviométrico de $1.508 \mathrm{~mm}$, de acordo com a tabela 1 . 
Tabela 1 - Dados climatológicos de Paraguaçu-MG.

\begin{tabular}{llllllllllllll}
\hline & Jan & Fev & Mar & Abr & Mai & Jun & Jul & Ago & Set & Out & Nov & Dez \\
\hline Tem. Max $\left({ }^{\circ} \mathrm{C}\right)$ & 23,4 & 23,0 & 24,1 & 20,1 & 17,3 & 16,7 & 17,8 & 19,7 & 21,1 & 22,1 & 22,6 & 21,4 \\
\hline Tem. Min $\left({ }^{\circ} \mathrm{C}\right)$ & 29,1 & 28,8 & 27,6 & 26,1 & 24,5 & 24,3 & 25,5 & 27,2 & 27,8 & 28,1 & 28 & 27,3 \\
\hline Chuva (mm) & 264 & 192 & 170 & 74 & 51 & 32 & 27 & 28 & 69 & 137 & 184 & 280 \\
\hline
\end{tabular}

FONTE: Climate-Date.Orgwebsite (2021)

Implantado no mês de novembro de 2020, o experimento foi conduzido até julho de 2021. Foi utilizando um talhão da cultivar Catucai Amarelo 24/137, de Coffea arabica L, implantada no ano de 2017 com espaçamento de 3,7 x 0,7 m totalizando um total de 4.158 plantas por hectare.

O delineamento experimental foi em blocos casualizados, utilizando-se 5 fontes de nitrogênio: ureia complexada com $46 \%$ de $\mathrm{N}$ onde parte do $\mathrm{NH}_{4}{ }^{+}$produzido após a hidrólise da ureia é adsorvido ou fixado nas estruturas dos ácidos húmicos, além dos ácidos húmicos serem inibidores da uréase, diminuindo a taxa de hidrólise da ureia, e possuir alta CTC (MOSCARDINI, 2019)., ureia convencional com $46 \%$ de $\mathrm{N}\left[\mathrm{CO}\left(\mathrm{NH}_{2}\right)_{2}\right]$ que é hidrolisada pela enzima urease, resultando na formação de carbonato de amônio [CO $\left(\mathrm{NH}_{2}\right)_{2}+2 \mathrm{H}_{2} \mathrm{O} \rightarrow$ $\left(\mathrm{NH}_{4}\right)_{2} \mathrm{CO}_{3}$ ], que se decompõe rapidamente, originando amônio, bicarbonato e hidroxila $\left[\left(\mathrm{NH}_{4}\right)_{2} \mathrm{CO}_{3}+\mathrm{H}_{2} \mathrm{O} \rightarrow 2 \mathrm{NH}_{4}{ }^{+}+\mathrm{OH}^{-}+\mathrm{HCO}_{3}^{-}\right]$, (ERNANI et al., 2001; ROCHETTE et al., 2009b), ureia de liberação controla com $42 \%$ de N que contem grânulos revestidos com enxofre que fornecem o $\mathrm{N}$ de forma gradual e reduz perdas. Além disso, ocorre a redução da emissão de $\mathrm{N}_{2} \mathrm{O}$, uma vez que a liberação gradual distribui o nitrogênio gradual ao longo tempo, e reduz as altas concentrações no solo, inclusive em anaerobiose que ocorre em situações de excesso de umidade, condições favoráveis a desnitrificação (ALMEIDA, 2014)., blend de ureia de liberação controlada com ureia protegida e ureia protegida com $46 \%$ de $\mathrm{N}$ onde os granulo é revestido com polímeros que recobre a sua superfície com uma barreira física semipermeável, que permite a solubilidade gradual do nutriente no solo (PEREIRA et al.,2009), essa liberação é controlada pela umidade e temperatura do meio, e o controle, onde recebeu somente aplicação de composto orgânico. Cada parcela experimental foi constituída com 3 linhas de plantio com 12 plantas cada, resultando em 36 
plantas por parcela sendo avaliada as 6 plantas centrais, instaladas em 4 repetições, totalizando 24 parcelas experimentais.

As plantas avaliadas tiveram um ramo do terço médio de cada lado da planta marcados com barbante, onde foi realizado as avaliações.

Todas as parcelas experimentais receberam a aplicação do composto orgânico, inclusive as controle, o qual tem a composição de N: 0,91\%, P:1,61\%, K: 2,04\%, Ca: 3,49\%, Mg: 2,94 \% e S: 1,34\%. Não houve variação de dose do composto orgânico nem do nitrogênio. Somente variação de fonte e parcelamento da dose, de acordo com o tradicionalmente utilizado e recomendado tecnicamente, conforme tabela 2.

Tabela 2: Descrição dos tratamentos, doses e parcelas.

\begin{tabular}{|c|c|c|c|c|c|c|c|}
\hline Tratamento & $\begin{array}{l}\mathrm{Kg} \mathrm{N} \\
\mathrm{ha}^{-1}\end{array}$ & $\begin{array}{c}\mathrm{Kg} \\
\text { Composto } \\
\text { Orgânico } \\
\text { ha }\end{array}$ & $\begin{array}{l}\text { Fonte de } \\
\text { Nitrogênio }\end{array}$ & $\begin{array}{c}1^{\circ} \\
\text { Parcela } \\
\mathrm{Kg} \mathrm{N} / \mathrm{ha}\end{array}$ & $\begin{array}{c}2^{\circ} \\
\text { Parcela } \\
\text { Kg N/ha }\end{array}$ & $\begin{array}{c}3^{\circ} \\
\text { Parcela } \\
\text { Kg N/ha }\end{array}$ & $\begin{array}{c}4^{\circ} \\
\text { Parcela } \\
\mathrm{Kg} \mathrm{N} / \mathrm{ha}\end{array}$ \\
\hline & & $04 / 12 / 20$ & & $18 / 12 / 20$ & $18 / 01 / 21$ & $18 / 02 / 21$ & $18 / 03 / 21$ \\
\hline $\mathrm{T} 1$ & 0 & 6000 & - & - & - & - & - \\
\hline T2 & 405 & 6000 & $\begin{array}{c}\text { Ureia } \\
\text { Complexada }\end{array}$ & 119 & 119 & 119 & - \\
\hline T3 & 405 & 6000 & $\begin{array}{c}\text { Ureia } \\
\text { Convencional }\end{array}$ & 89,3 & 89,3 & 89,3 & 89,3 \\
\hline T4 & 405 & 6000 & $\begin{array}{l}\text { Ureia de } \\
\text { liberação } \\
\text { controlada (6 } \\
\text { meses) }\end{array}$ & 357 & - & - & - \\
\hline T5 & 405 & 6000 & $\begin{array}{c}\text { Blend }(70 \% \\
\text { ureia } \\
\text { liberação } \\
\text { controlada + } \\
30 \% \text { ureia } \\
\text { Protegida }\end{array}$ & 357 & - & - & - \\
\hline T6 & 405 & 6000 & $\begin{array}{l}\text { Ureia } \\
\text { Protegida }\end{array}$ & 89,3 & 89,3 & 89,3 & 89,3 \\
\hline
\end{tabular}

O parcelamento das doses foi realizado 30 dias após cada aplicação, nesse período também foi realizado o acompanhamento e monitoramento da área, onde foi avaliado o 
crescimento dos ramos (ALFONSI, 2008) nível de enfolhamento e incidência de pragas e doenças.

Todos os tratamentos receberão o fornecimento de $\mathrm{P}, \mathrm{K}$ e micronutrientes de acordo com Guimarães et al (1999).

Após 52 dias da última aplicação dos fertilizantes, foi realizado a coleta de folhas e enviadas para análise laboratorial segundo metodologia proposta por Martinez et al. (2003), para avaliar os níveis de nitrogênio, bem como sua interação com os demais nutrientes. Foram coletadas as folhas do $3^{\circ}$ e o $4^{\circ}$ par dos ramos plagiotropicos do terço médio do cafeeiro, no período em que as plantas encontravam se em estágio de maturação dos frutos.

Foram avaliadas as produções de seis plantas úteis, colhidas por derriça no pano, quando apresentavam aproximadamente $5 \%$ de frutos verdes, os frutos foram submetidos a secagem em terreiro de cimento até atingirem o percentual de 11,5\% de umidade, quando foram submetidos ao beneficiamento. A quantidade de café beneficiado por parcela útil foi então convertida em produção de sacas de $60 \mathrm{~kg}$ por hectare.

Os resultados levantados foram submetidos à análise de variância e a comparação das médias feitas pelo teste de Scott-Knott, a 5\% de probabilidade, ambos utilizando 0 software SISVAR ${ }^{\circledR}$ (FERREIRA, 2014).

\section{RESULTADOS E DISCUSSÃO}

Após a análise de variância, os níveis de nitrogênio foliares apresentaram diferenças significativa entre as fontes de nitrogênio utilizadas, se destacando a ureia convencional, conforme apresentado no Gráfico 1. 
Gráfico 1: Teor de Nitrogênio foliar (\%).

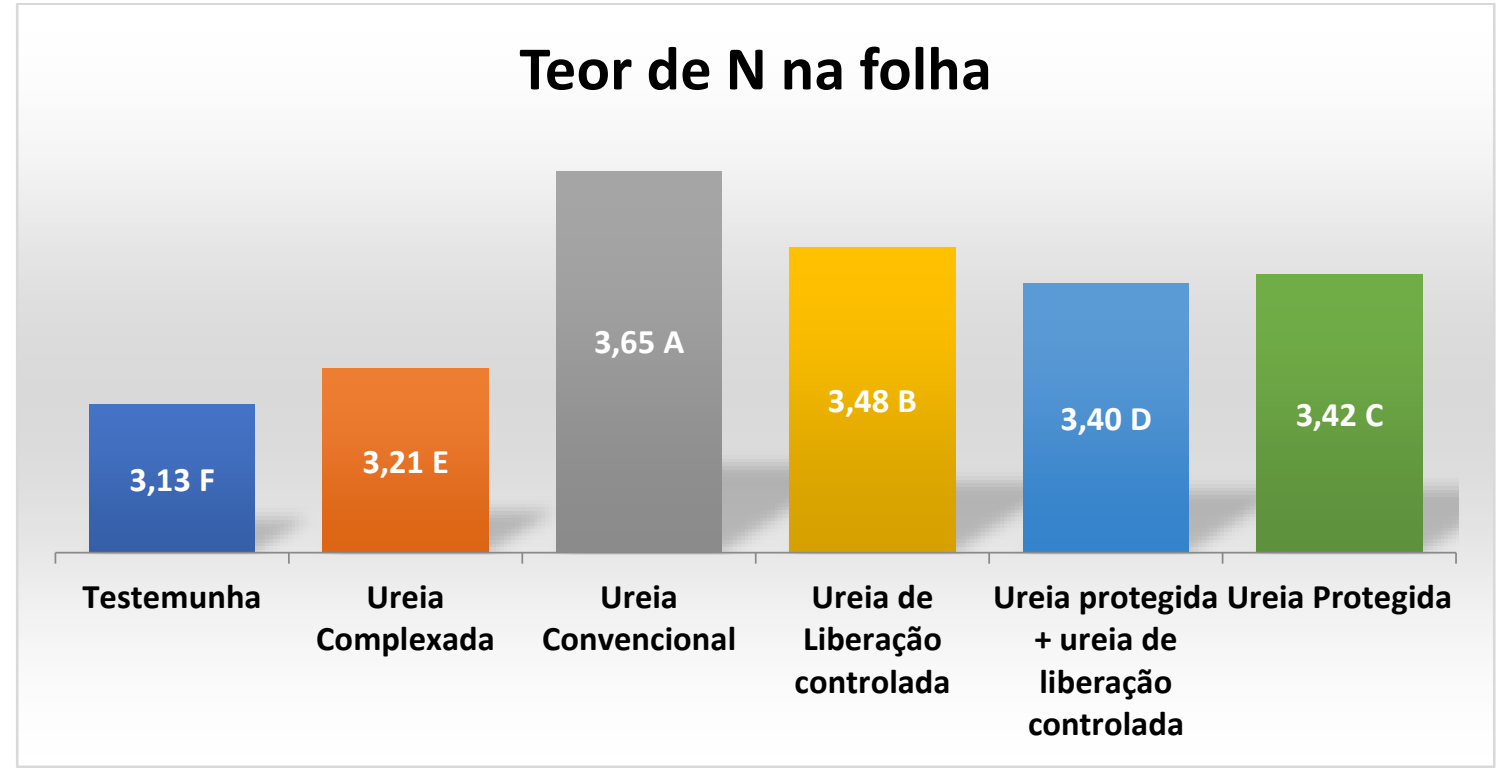

*Médias, seguidas da mesma letra, não diferem entre si, pelo teste de Scott- Knott, a 5\% de significância.

Fonte: Autor

$\mathrm{O}$ acumulo de $\mathrm{N}$ foliar foi influenciado de acordo com as fontes utilizadas, sendo a ureia convencional aplicada de forma parcelada a que resultou em maior acumulo de nitrogênio no tecido foliar. Segundo Lima et al., (2015), métodos como parcelamento da adubação reduzem as perdas, aumentando a eficiência da adubação e Garcia, (2020) complementa que o uso de ureia comum exige a aplicação parcelada para se obter um maior aproveitamento. Entretanto ABRANCHES, (2016) em seu trabalho demostrou que o uso de ureia revestida proporciona maior acumulo de $\mathrm{N}$ nas folhas. Já DOMENGUTTI, (2016) em sua pesquisa obteve resultados que afirmam que os teores de $\mathrm{N}$ acumulado nas folhas não tiveram diferenças estatísticas em relação as fontes utilizadas, porem ressalta que há diferença nos teores entre as épocas avaliadas.

Todos os tratamentos obtiveram resposta ao acúmulo de $\mathrm{N}$ foliar quando comparamos com a testemunha, para Reis et al., (2009) a assimilação do nitrogênio resulta diretamente no desenvolvimento das plantas. condiçionando a possibilidade de obtenção de boas produções.

No crescimento dos ramos plagiotrópicos, número de entrenós e enfolhamento, Gráfico 2, 3 e 4 não apresentaram diferenças significativas entre os tratamentos onde todos se equipararam estatisticamente a testemunha, resultados semelhantes de um trabalho realizado por Leite et al., (2017). 
Gráfico 2: Crescimento do ramo plagiotrópico em cm

\section{Comprimento do Ramo Plagiotrópico}

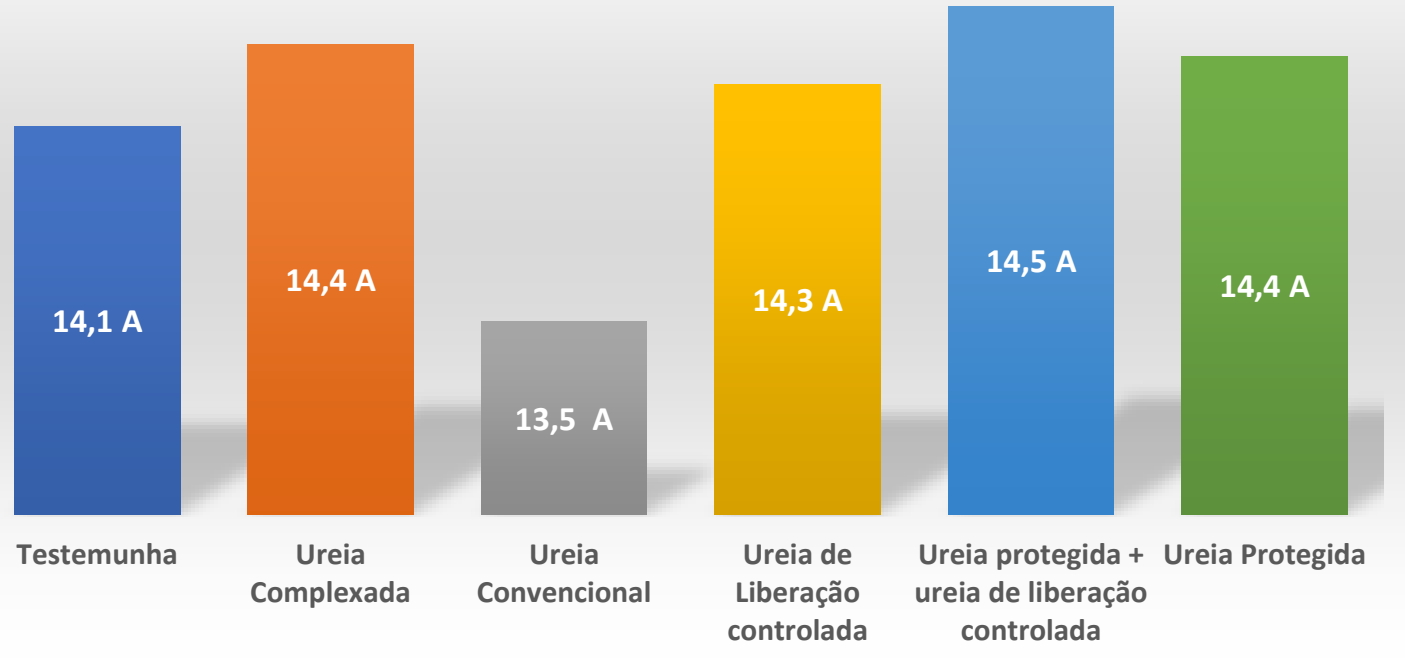

*Médias, seguidas da mesma letra, não diferem entre si, pelo teste de Scott- Knott, a 5\% de significância.

FONTE: Autor

Gráfico 3: Número médio de entrenós por ramos

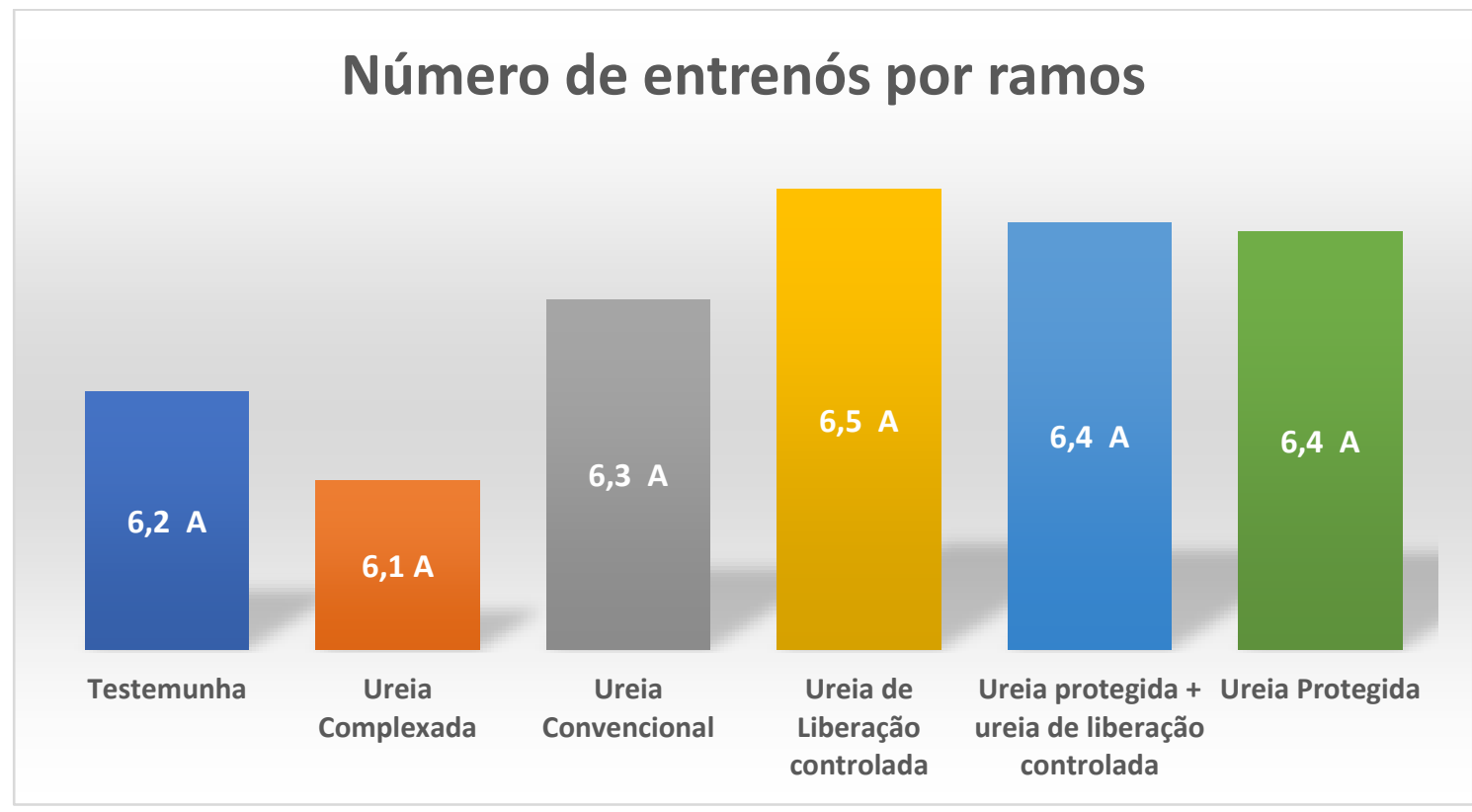

*Médias, seguidas da mesma letra, não diferem entre si, pelo teste de Scott- Knott, a 5\% de significância.

FONTE: Autor 
Gráfico 4: Índice de enfolhamento (\%)

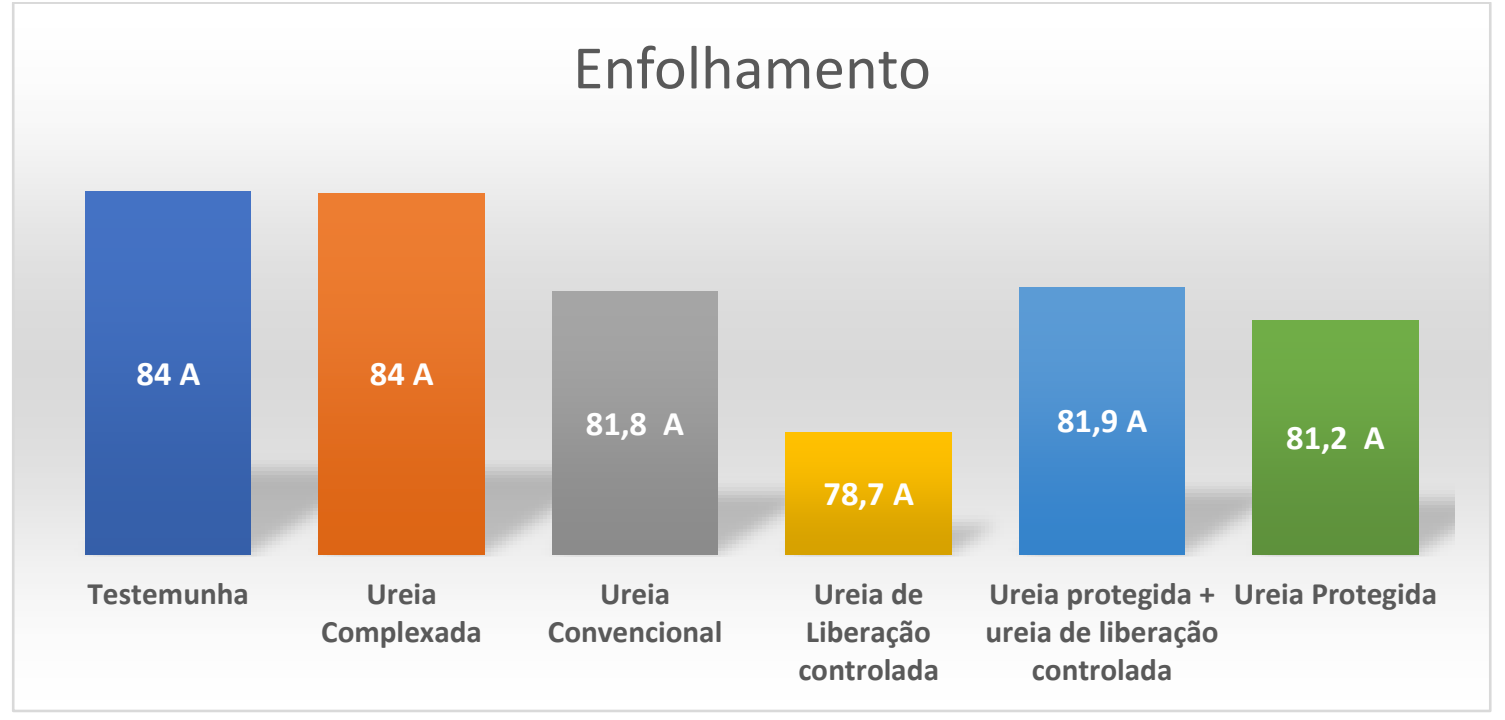

*Médias, seguidas da mesma letra, não diferem entre si, pelo teste de Scott- Knott, a 5\% de significância.

FONTE: Autor

Ao verificarmos os dados, todos os tratamentos se equipararam, mas ressaltamos importância do nitrogênio para as variáveis analisadas, pois exerce um papel fundamental nos vegetais, está diretamente ligado ao crescimento e desenvolvimento das plantas formação de folhas, gemas floríferas e frutíferas Teixeira et al., 2013, fatores que estão diretamente ligados a produção do cafeeiro (BRAGANÇA et al., 2015). Lima et al. (2016), também mostraram correlação positiva com as doses de $\mathrm{N}$ em relação ao aumento no comprimento dos ramos plagiotrópicos.

Garcia, (2020) afirma que o uso de diferentes fontes de nitrogênio, não influencia na quantidade de nós dos ramos, entretanto, (FRANCO, 2019) na sua pesquisa afirma que o uso de fontes de liberação lenta promove melhor crescimento dos ramos do cafeeiro.

O rendimento café colhido para produção de uma saca de café beneficiado, que é uma variável muito importante a qual foi analisada, pois é a que vai demonstrar a produção de cada tratamento, tivemos o tratamento com ureia de liberação controlada sendo o que se diferenciou estatisticamente dos demais sendo superior, seguindo pelos tratamentos com ureia convencional e protegida se assemelharam estatisticamente e foram superiores a testemunha. Já o tratamento com ureia complexada se assemelhou estatisticamente a testemunha como mostra o gráfico 5. 
Gráfico 5: Rendimento em litros por saco - renda.

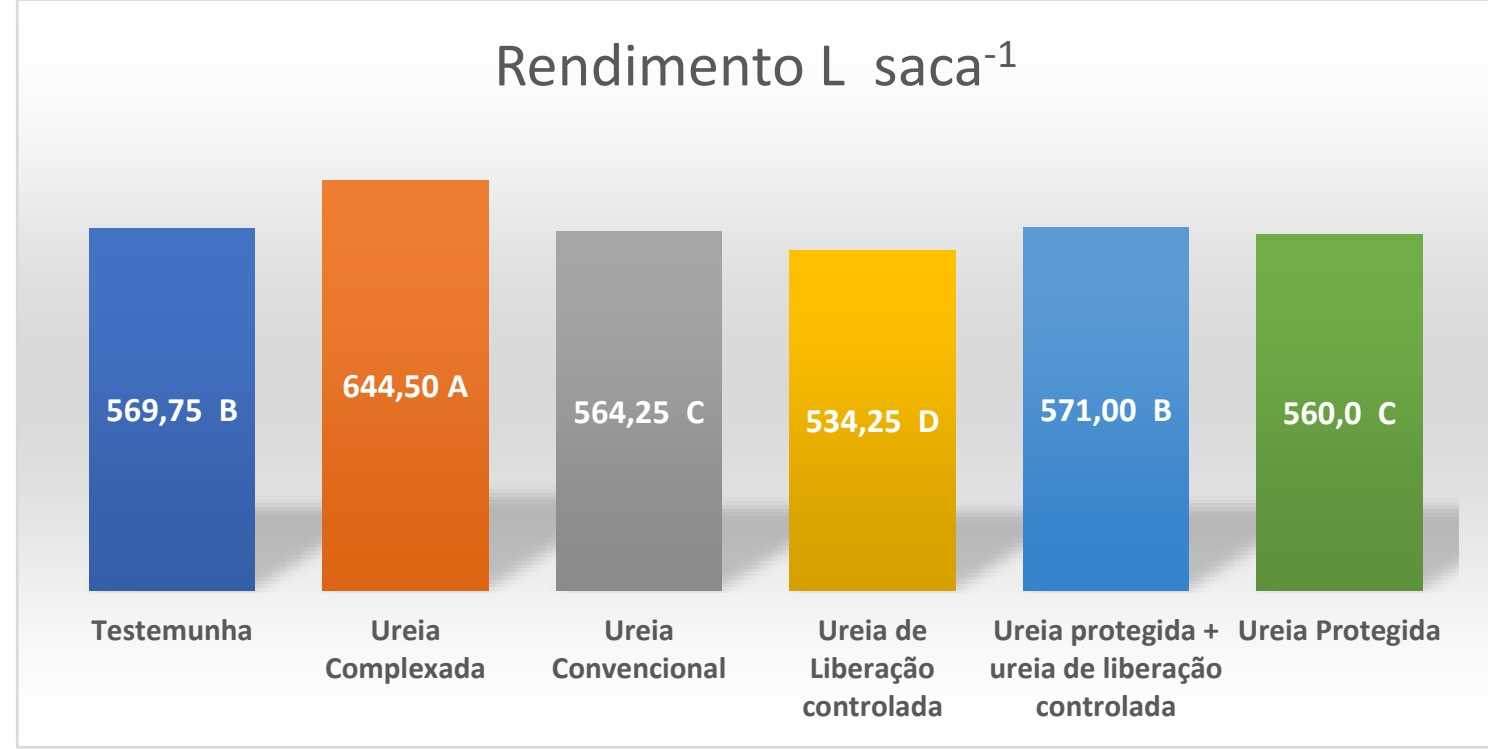

*Médias, seguidas da mesma letra, não diferem entre si, pelo teste de Scott- Knott, a 5\% de significância.

FONTE: Autor

Venturim et al., (2018) nos fala que a fonte utilizada para o fornecimento de $\mathrm{N}$ influenciará diretamente na produtividade e Lima (2012) afirma que o N está relacionado diretamente com crescimento e produção do cafeeiro, além de ser fundamental para garantir a alta produtividade (PEDROSA et al., 2014).

Abranches (2018) afirma que a adubação nitrogenada influencia positivamente as características biométricas das plantas de café como diâmetro, altura, número de nós, comprimento do ramo, teor de $\mathrm{N}$ foliar e a produtividade das plantas.

As diferentes fontes nitrogenadas apresentaram efeito sobre a produção da cultura do cafeeiro (CARVALHO et al., 2016), e o uso de nutrientes em forma de liberação controlada propicia um aumento na produtividade (SILVA et al., 2013).

Franco Junior et al, (2019), utilizando fertilizante de liberação controlada em cafés desde a sua formação até a primeira produção, resultou em diferença positiva de 3,2 sacas em relação ao padrão com uso de $\mathrm{N}$ convencional, destacando que a liberação gradativa e redução das perdas, resulta em incrementos de produtividade.

Bartelega (2018) Avaliando diferentes tecnologias em fertilizantes nitrogenados, não verificou diferenças em relação a produtividade do cafeeiro. 


\section{CONCLUSÕES}

Conclui se que a ureia complexada proporcionou o melhor rendimento de litros de café colhido para produzir uma saca beneficiada e a ureia convencional em acumulo de $\mathrm{N}$ foliar.

\section{REFERÊNCIAS}

ABIC - Associação Brasileira da Industria de Café. $O$ café brasileiro na atualidade. 2021. Disponível em: < https://www.abic.com.br/o-cafe/historia/o-cafe-brasileiro-naatualidade-2/> Acesso em: 19 de julho de 2021.

ABRANCHES, J. L. Resposta da cultura do café arábica à aplicação de ureia revestida. Faculdade de Ciências Agronômicas da Unesp Campus de Botucatu, Botucatu, SP, 2018. Disponível em https://repositorio.unesp.br/bitstream/handle/11449/152971/abranches_jlme_botfca.pdf?s equence=3\&isAllowed=y . Acesso em 31 de outubro de 2021 .

ALFONSI, E. L. Uso de índices fenológicos em modelos de previsão de produtividade do cafeeiro. 2008. 104 f. Tese (Doutorado em Fitotecnia) Escola Superior de Agricultura Luiz de Queiroz, Piracicaba, 2008.

\section{ALMEIDA, R.E.M. Fertilização nitrogenada no consórcio milho-braquiária} em solos de clima tropical úmido no sistema de integração lavourapecuária. Thesis (PhD), Escola Superior de Agricultura Luiz de Queiroz. Universidade de São Paulo. Piracicaba. 2014.

BRAGANÇA, S. M. et al. Acúmulo de B, Cu, Fe, Mn e Zn pelo cafeeiro conilon. Ceres, Viçosa, v. 54, n. 314, p. 398-404, 2015.

BARTELEGA, L. Fertilizantes nitrogenados convencionais, estabilizados, de liberação lenta, controlados e blendes para o Cafeeiro. Dissertação (mestrado acadêmico) Universidade Federal de Lavras, 2018. 68p.

CANTARELLA, H. Nitrogênio. In NOVAIS, R. F.; ALVAREZ, V. H.; BARROS, N. F. FONTES, R. L. F.; CANTARUTTI, R. B.; NEVES, J. C. L., eds. Fertilidade do solo. Viçosa, Sociedade Brasileira de Ciência do Solo pp.375-470, 2007.

CARVALHO, L. E; et al. Eficiência de diferentes adubos nitrogenados sobre a produção do cafeeiro. Bambuí, MG 2016. Disponível em bicafe.ufv.br/bitstream/handle/123456789/10026/448_42-CBPC-2016.pdf?sequence=1. Acesso em 28 de outubro de 2021.

CLIMATE. DATA. 2020. Disponível em: <https://pt.climate-data.org/america-dosul/brasil/minas-gerais/paraguacu-176430/>. Acesso em 08 maio 2020. 
DOMINGHETTI, A. W. et al. Nitrogen loss by volatilization of nitrogen fertilizers applied to coffee orchard. Ciência e Agrotecnologia, Lavras, v. 40, n. 2, p. 173-183, mar./abr. 2016.

EMATER. Manual do Café: Manejo de Cafezais em Produção. Belo Horizonte, 2016.

Disponível em: <

http://www.sapc.embrapa.br/arquivos/consorcio/publicacoes_tecnicas/livro_manejo_cafez ais_producao.pdf> Acesso em: 19 de julho de 2021.

EMBRAPA - Empresa Brasileira de Pesquisa Agropecuária Ministério da Agricultura, Pecuária e Abastecimento. O futuro da agricultura Brasileira. Visão 2030. Brasília, 2018. Disponível em: <

https://www.embrapa.br/documents/10180/9543845/Vis\%C3\%A3o+2030++o+futuro+da+agricultura+brasileira/2a9a0f27-0ead-991a-8cbf-

af8e89d62829?version=1.1 > Acesso em: 19 de julho de 2021.

ERNANI, P.R.; BAYER, C. \& STECKLING, C. Características químicas de solo e rendimento de matéria seca de milho em função do método de aplicação de fosfatos, em dois níveis de acidez. R. Bras. Ci. Solo, v. 25, pp. 939-946, 2001.

FRANCO JUNIOR, KS; CARVALHO, JS; GUIMARÃES, BC; BARBOSA, CKR; BRIGANTE, GP; DIAS, M. de S .; APRELINI, A .; SILVA, N. de O. AVALIAÇÃO DO ADUBO DE LIBERTAÇÃO LENTA NO DESENVOLVIMENTO INICIAL E PRODUCĈ̃̃ DE CAFÉ. Coffee Science - ISSN 1984-3909 , [S. I.] , v. 14, n. 4, pág. 538-543, 2019.

Disponível em:

http://www.coffeescience.ufla.br/index.php/Coffeescience/article/view/1651. Acesso em: 15 nov. 2021.

FERREIRA, D. F. Sisvar: a computer statistical analysis system. Ciência e Agrotecnologia, v. 35, n. 6, p.1039-1042, 2014.

GARCIA, J. V. Diferentes fontes de nitrogênio na adubação do cafeeiro (coffea arabica I.). Revista educação, saúde \& meio ambiente vol. 1, ano 4, n. 7, p. 176-186, 2020.

GUIMARÃES, et al; COMISSÃO DE FERTILIDADE DO SOLO DO ESTADO DE MINAS GERAIS. Recomendações para o uso de corretivos e fertilizantes 1999 em Minas Gerais - 5 ${ }^{\mathrm{a}}$ Aproximação. - Viçosa, MG, 1999. 289-302p.

LEITE, B. C. et al. DESENVOLVIMENTO INCIAL DE PLANTAS DO CAFEEIRO UTILIZANDO DIFERENTES FERTILIZANTES NITROGENADOS. Seminario de iniciação cientifica IFMG. - Bambuí, MG, 2017. Disponível emhttps://www.ifmg.edu.br/sic/edicoes-anteriores/resumos-2017/desenvolvimento-inicalde-plantas-do-cafeeiro-utilizando-diferentes-fertilizantes.pdf. Acesso em 08 de dezembro de 2021.

LIMA, E., et al. Nitrogênio na cultura do Café Cofeea arábica. Cultivando o saber. Cascavel, v.5, n.2, p.9-17, 2012. Disponível em https://cultivandosaber.fag.edu.br/index.php/cultivando/article/view/422. Acessado em 30 de outubro de 2021. 
LIMA, L.C. et al. Crescimento e produtividade do cafeeiro irrigado, em função de Lima, L. C. de et al. diferentes fontes de nitrogênio. Coffee Science, Lavras, v. 11, n. 1, p. 97 107, jan./mar. 2015. Disponível em

http://200.235.128.121/bitstream/handle/123456789/8177/Coffee\%20Science_v11_n1_p9 7-107_2016.pdf?sequence=1\&isAllowed=y. Acesso em 31 de outubro de 2021.

MARTINEZ, H. E. P.; et al. Faixas críticas de concentrações de nutrientes e avaliação do estado nutricional de cafeeiros em quatro regiões de Minas Gerais. Pesquisa

Agropecuária Brasileira, Brasília, v. 38, n. 6, p. 703-713, 2003.

MIRANDA, G. B. Poda programada de ciclo do café arábica, aspectos: morfológicos e produtivos. Tese de doutorado. Universidade Estadual Do Norte Fluminense Darcy Ribeiro, Campos Dos Goytacazes, 2019. Disponível em: < https://uenf.br/posgraduacao/producao-vegetal/wp-content/uploads/sites/10/2019/10/TeseGuilherme.pdf> Acesso em: 19 de julho de 2021.

MOSCARDINI. D. Ureia complexada no cafezal: O que existe de concreto sobre esta prática? Revista Attalea Agronegócios, v. 8, 2019. Disponível em https://revistadeagronegocios.com.br/davi-moscardini-ureia-complexada-no-cafezal-o-queexiste-de-concreto-sobre-esta-pratica/. Acesso em 08 de novembro de 2021.

NAZARENO, R. B. et al. Crescimento inicial do cafeeiro Rubi em resposta a doses de nitrogênio, fósforo e potássio e a regimes hídricos. Pesquisa Agropecuária Brasileira, Brasília, v. 38, n. 8, p. 903-910, 2003.

PEDROSA, A. W., FAVARIN, J. L., VASCONCELOS, A. L. S. Resíduo de brachiaria fertilizada com nitrogênio na adubação do cafeeiro. Coffee Science, Lavras, v. 9, n. 3, p. 366-373, jul./set. 2014.

PEREIRA, Hamilton Seron et al.Ammonia volatilization of urea in the out-of-season corn. Revista Brasileira de Ciência do Solo, Viçosa, v. 33 n. 6, p. 1685-1694, 2009.

QUINTELA, P. et al. Parâmetros produtivos e nutricionais do cafeeiro submetido adubação nitrogenada. Revista Caatinga, v. 24, n. 4, pp. 74-79. 2011, Disponível em: https://www.redalyc.org/articulo.oa?id=237120127012. Acessado em 31 de outubro de 2021.

REIS, A. R. et al. Atividade do nitrato redutase e glutamina sintetase em folhas de café durante o desenvolvimento do fruto. Revista Brasileira de Ciência do Solo, Viçosa, v. 33, p. 315-324, 2009.

ROCHETTE, P.; ANGERS, D.; CHANTINI, M.H.; MacDONALD, J.D.; GASSER, M. \& BERTRAND, N. Reducing ammonia volatilization in a no-till soil by incorporating urea and pig slurry in shallow bands. Nutr. Cycling Agroecosyst., v. 84, pp. 71-80, 2009.

SILVA, F. R.; et al. Fertilizantes de liberação controlada na adubação de solo em cafeeiros coffea arábica em produção. Araxá MG 2016. Disponível em http://handbook.usfx.bo/nueva/vicerrectorado/citas/AGRARIAS_7/AGRONOMIA/ANAISXII-MOSTRA-DE-PESQUISA.pdf\#page=32. Acesso em 31 de outubro de 2021. 
TEIXEIRA, W. F.; et al. Atividade da enzima nitrato redutase e crescimento de Swietenia macrophylla King sob efeito de sombreamento. Floresta e Ambiente, v. 20, n. 1, p. 9198, 2013.

VENTURIM, C. H. P., FERREIRA, G. H., SILVA, A. M. Resposta do cafeeiro à adubação nitrogenada com inibidores de urease comparada à convencional. $44^{\circ}$ Congresso Brasileiro de Pesquisas Cafeeiras Poços de Caldas MG, 2018 Disponível em http://www.sbicafe.ufv.br/bitstream/handle/123456789/11749/262_44-CBPC2018.pdf?sequence=1, Acesso em 30 de outubro de 2021. 


\begin{abstract}
The nutritional balance of the coffee tree is essential to achieve high yields. Nitrogen is the nutrient most demanded by the coffee crop, being its supply most used from urea sources, which is subject to losses by ammonia volatilization when applied without incorporation or low levels of moisture in the soil. Therefore, we sought to evaluate the effects of different nitrogen sources with different technologies on the fertilization of Arabica coffee in production. For this, the cultivar Catucai Amarelo 24/137 was used, and five nitrogen sources were applied: complexed urea, conventional urea, controlled-release urea, blend of controlled-release urea with protected urea and protected urea. It is concluded that the complexed urea provided the best yield of liters of harvested coffee to produce a benefited bag and the conventional urea in leaf $\mathrm{N}$ accumulation.
\end{abstract}

Keywords: Ammonification. Ammonia. Coffea arabica, Nutrition. Volatilization.

\title{
RESUMEN
}

El equilibrio nutricional del cafeto es fundamental para lograr altos rendimientos. El nitrógeno es el nutriente más demandado por el cultivo del café, siendo su aporte el más utilizado a partir de fuentes de urea, la cual está sujeta a pérdidas por volatilización del amoniaco cuando se aplica sin incorporación o con bajos niveles de humedad en el suelo. Por lo tanto, buscamos evaluar los efectos de diferentes fuentes de nitrógeno con diferentes tecnologías sobre la fertilización del café Arábica en producción. Para ello se utilizó el cultivar Catucai Amarelo 24/137 y se aplicaron cinco fuentes de nitrógeno: urea complejada, urea convencional, urea de liberación controlada, mezcla de urea de liberación controlada con urea protegida y urea protegida. Se concluye que la urea complejada proporcionó el mejor rendimiento de litros de café cosechado para producir una bolsa beneficiada y la urea convencional en acumulación de $\mathrm{N}$ foliar.

Palabras clave: Amonificación. Amoniaco. Nutrición. Coffea arabica. Volatilización. 


\section{LICENÇA DE USO}

Este é um artigo publicado em acesso aberto (Open Access) sob a licença Creative Commons Atribuição 4.0 Internacional (CC BY 4.0), que permite uso, distribuição e reprodução em qualquer meio, desde que o trabalho original seja corretamente citado. Mais informações em: http://creativecommons.org/licenses/by/4.0

\section{CONFLITO DE INTERESSES}

Os autores declaram que não há conflito de interesses neste trabalho.

\section{CONTRIBUIÇÕES AUTORAIS}

Autor 1: Responsável pela autoria do texto e condução dos trabalhos a nível de campo. Autor 2: Responsável pela autoria do texto, revisão e análise de dados e apoio metodológico.

Autor 3: Responsável pela autoria do texto, revisão e análise de dados.

Autor 4: Responsável pela autoria do texto, revisão e análise de dados e correções ortográficas.

Autor 5: Apoio na execução de campo.

FINANCIAMENTO

O presente trabalho não contou com apoio financeiro.

\section{COMO REFERENCIAR}

CAIXETA, Elber Augusto et al. Avaliação de diferentes fontes de nitrogênio na cultura do café. Revista Brasileira de Engenharia de Biossistemas (Tupã), v. 15, n. 4, p. 617-631, 2021. DOI: http://dx.doi.org/10.18011/bioeng2021v15n4p617-631.

\section{RESPONSABILIBADE EDITORIAL}

Prof. Dr. Fernando Ferrari Putti ${ }^{1}$, Prof. Dr. Paulo Sérgio Barbosa dos Santos ${ }^{1}$, Prof. Dr. Eduardo Festozo Vicente ${ }^{1}$ e Prof. Dr. Diogo de Lucca Sartori ${ }^{1}$

${ }^{1}$ Universidade Estadual Paulista "Júlio de Mesquita Filho", FCE - Faculdade de Ciências e Engenharia, Tupã, SP, Brasil. 